\title{
Ontology Application for the Organizational Goals
}

\author{
Tengku Adil Tengku Izhar \\ Faculty of Information Management \\ Universiti Teknologi MARA \\ UiTM Selangor, Malaysia \\ Mohd Shamsul Mohd Shoid \\ Faculty of Information Management, \\ Universiti Teknology MARA, \\ UiTM Selangor, Malaysia
}

Received: Jul. 19, 2020 Accepted: Sep. 29, 2020 Online published: Oct. 16, 2020

doi:10.5296/ijhrs.v10i4.17839 URL: https://doi.org/10.5296/ijhrs.v10i4.17839

\begin{abstract}
Data is important in assisting decision-making in relation to the organizational goals. However, the trustworthiness of organizational data in relation to achieving the organizational goals is often questioned because of the vast amount of organizational data available. This paper advances the understanding of the organizational goals model based on ontology. This refers to the importance of assisting the organization to utilize relevant organizational data for decision-making in relation to the organizational goals. Therefore, domain experts and entrepreneurs can make a decision to what extend the organizational goals are achieved. The results show that ontology supports the relationship between the organizational goal elements as an effort to measure organizational data in relation to the organizational goals.
\end{abstract}

Keywords: evaluation, metrics, organizational data, organizational goals, ontology

\section{Introduction}

Today people have access to more data in single day than most people that have access to data in the previous decade. The problem is the data found in many different forms. All this data captures in different formats and makes it almost impossible to understand the existing relationship between different data. For example, CEOs of organizations have certain requirements of the data they receive as they use this data to support the decision making process to achieve organizational goals. In today's technological age, organizations 
accumulate a huge amount of data, and information technology has developed beyond the storage, transmission and processing of data (Seng \& Chen, 2010). Organizations rely on resources such as data, information and knowledge to assist the development of the business plan, the design of business strategies and decision-making. Organizational resources such as data must be relevant to assist the decision making process in relation to the organizational goals. Typically, relevant data for decision-making is extracted from the organization's data sources (Romero \& Abello, 2010). Therefore, organizations should have the ability to manage their resources (Omerzel \& Antoncic, 2008; Schalenkamp \& Smith, 2008; Smith et al., 2007). However, the growth in the amount of the organizational resources available nowadays poses major difficulties as well as challenges to decision-making (Mikroyannidis \& Theodoulidis, 2010). Professional such as data analysts are trained to analyse organizational data but the dramatic increase in the amount of available organizational resources has become a major problem in applying organizational data. Clearly, this is because they do not have enough accurate and relevant data to enhance the reliability of decision-making. Even though organizations have a vast amount of the data, they may not have the data that they really need. Thus, the reliability of organizational data in relation to meeting organizational goals is often in doubt which raises the question as to how to optimise the selected data to improve decision making to achieve organizational goals. Organizational goals are defined as the most important targets to be achieved in every organization. At the same time, even though the concept of organizational goals has been in existence for some time, modelling the structure of organizational goals is much more difficult (Izhar et al., 2012; Izhar et al., 2013). Therefore, we suggest ontology as one approach to develop a common understanding of the organizational goals structure (Izhar et al., 2013). An ontology provides explicit and formal specifications of knowledge, especially implicit or hidden knowledge (Cho et al., 2006). An ontology is considered as an approach to support data sharing (Pundt \& Bishr, 2002). Therefore, an ontology assists with part of the integration problem in relation to the organizational goals and can thus be used to improve the communication and collaboration between the decision makers and the users (Selma et al., 2012), which is, in our case, the decision makers in relation to the organizational goals.

The aim of this paper is to propose a model for the organizational goals based on ontology in order to evaluate the level of the organizational goals achievement. In order to achieve this aim, the model aims to provide a solution to identify the dependency relationship between the organizational goals elements. This paper begins by identifying the background of the organizational goals ontology and how ontology is use to improve the understanding of the dependency relationship of the organizational goals.

As part of the organizational goals ontology, we introduce an approach to analyse organizational data to consider whether this organizational data is relevant in relation to the organizational goals. In contrast to the models in Rao et al. ( 2012), Sharma \& Osei-Bryson (2008) and Fox et al. (1998), the model in this paper proposes an analysis approach to evaluate organizational data that relate to the organizational goals. The process is to specify to what extent the organizational goals are achievable. Therefore, future domain experts and entrepreneurs can come out with decision-making process in achieving the organizational 
goals so he/she can make a decision to what extend the organizational goals have been achieved. This provides knowledge to improve the applicability of the model so future approach can be suggested to address any gaps and issues in achieving the organizational goals.

A case study is presented to test the flexibility and applicability of the organizational goals ontology in a real world situation. At the same time, the case study will explores the real potential of the organizational goals ontology so it can be confirmed that it can be applied in many domains. The purpose of the case study is to validate the flexibility of the organizational goals ontology and to discover any issues or gaps which may be identified during the implementation and how these gaps can be addressed in future work.

The remainder of this paper is organized as follows. Section 2 is problem statements. The organizational goals model is discusses in Section 3. Section 4 is the introduction to the organizational goals ontology. Case study is in Section 5. Discussion is in Section 6. The final section contains some concluding remarks.

\section{Problem Statements}

Organizational goals defined as the most important targets to be achieved in every organization (Izhar et al., 2013). Even though the concept of the organizational goals has been in existence for some time, modelling the structure of the organizational goals is much more difficult (Izhar et al., 2012; Izhar et al., 2013). For example, one way to develop a common understanding of the organizational goals structure is based on ontology (Izhar et al., 2013). An ontology provides explicit and formal specifications of knowledge, especially implicit or hidden knowledge (Cho et al., 2006). An ontology is considered as an approach to support data dependencies (Pundt \& Bishr, 2002). Therefore, an ontology assists with part of the integration problem in relation to the organizational goals and can be used to improve the communication and collaboration between the decision makers and the users (Selma et al., 2012), which is, in this paper, the decision makers in relation to the organizational goals (Izhar et al., 2013).

There is a shortcoming when it comes to evaluate the organizational data in relation to the organizational goals during the development of the organizational modelling. Modelling the organizational goals is limited to business processes and organizational processes (Mark S Fox et al., 1996; Mark S. Fox et al., 1998; Mansingh et al., 2009; Rao et al., 2012; Sharma \& Osei-Bryson, 2008). Most of the previous studies argued that the need for and benefits from goal modelling focus on process modelling, workflow analysis, computer-supported cooperative work and design problem solving (Popova \& Sharpanskykh, 2011).

Despite this shortfall, there are a number of tools for the modelling organizational processes where most of these tools support mathematical modelling (Vergidis et al., 2008). Structuring a small organization is less complicated than a large organization. Different organizational structures, processes and a vast amount of data make it more difficult to identify relevant organizational data in relation to the organizational goals. Therefore, it is also important to identify metrics that can measure the relevance of organizational data in relation to the 
organizational goals.

However, in many ontology studies, there is a lack of tools reporting on such metrics (Rao et al., 2012; Valiente et al., 2012). We suggest that metrics is important to enable both domain experts and entrepreneurs to evaluate the relevance of organizational data in relation to the organizational goals (Izhar et al., 2013). Domain experts can identify the relevance of organizational data in achieving the organizational goals and measure the value of the analysed organizational data. Furthermore, the organizational goals ontology is important for assisting domain experts to apply such knowledge in relation to the organizational goals (Izhar et al., 2013).

\subsection{Problem Scope}

Previous research in this area has mainly examined the issue from the data process point of view that addresses either software development or data mining, both of which are beyond the scope of this thesis (Lee et al., 2008). While many studies have examined the process of data collection, our main contribution is to develop a framework which can incorporate organizational data and can lead to reliable decision-making in meeting the organizational goals. Therefore, it is important to develop a flexible and widely applicable framework to evaluate the relevance of organizational data to evaluate the level of the organizational goals achievement.

Most studies which have been conducted around this issue focus on business intelligent (BI) (Azma \& Mostafapour, 2012; Nofal \& Yusof, 2013; Popovic et al., 2012), data mining (Aghdaie et al., 2014; Weerdt et al., 2013; Zandi, 2014), data linkage (Christen, 2008; Durham et al., 2012; Ferrante \& Boyd, 2012) and knowledge discovery in databases (KDD) (Cheng et al., 2012; Lin et al., 2008). Even though these studies focus on the decision-making but they do not focus on the interaction between organizational data and organizational goals. Therefore, it is difficult to identify the relevance of organizational data that relate to the organizational goals.

For example KDD is an interdisciplinary field that searches for valuable information in large volumes of data and has played an important role in identifying effective patterns from a vast amount of data (Lee et al., 2008). KDD is a concept of identifying new knowledge in the field of the computer science that describes the process of searching a vast amount of data in order to produce knowledge and it missing the link to the organizational goals. However, KDD applies the concept within the system instead of searching and evaluating the organization data.

Another example is the business intelligence (BI). BI is a computer based technique to analyse the business data which provide past and current of the business strategies and business operation for the decision making. BI has been practice toward the competitive intelligence where BI aims to support better decision making process based on the past and current business strategies. BI aims to analyse the business data by providing the past and current data as a strategy to assist the decision making. Meanwhile, data linkage is a process to identify data from different datasets. Christen (Christen, 2012) defined data linkage as a 


\section{Macrothink

process of data pre-processing to identify quality data.

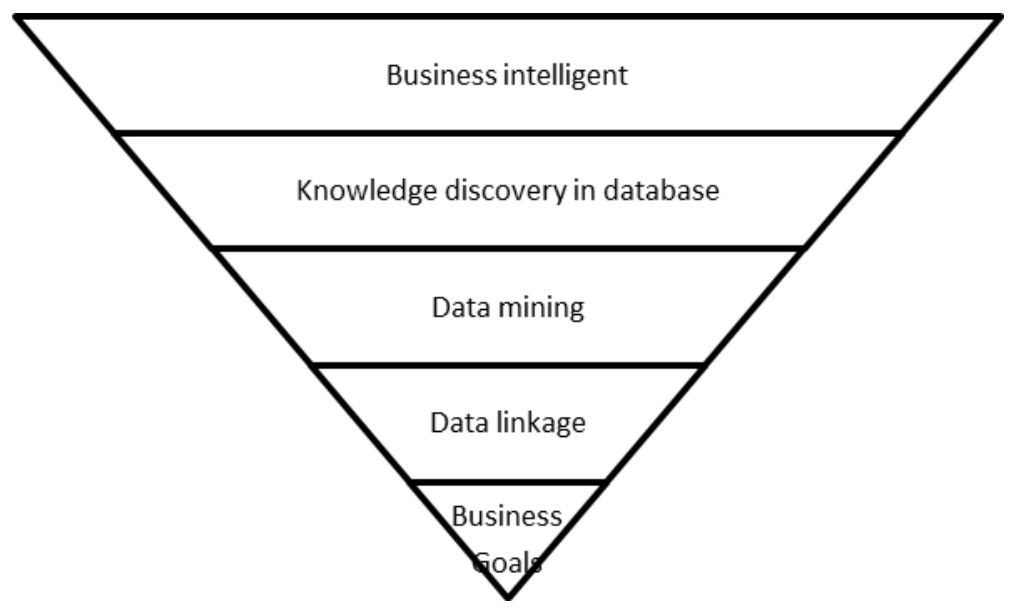

Figure 1. Problem scope

In this paper, we tackle the problem to evaluate the organizational goals by proposing the organizational model based on ontology to assist the decision-making process in relation to the organizational goals. We propose this model as a platform to evaluate the organizational data in order to support decision-making and thereby assist the organization to achieve its goals. We suggest that the organizational goals ontology is important in an effort to evaluate the relevance of organizational data. This framework is also important in measuring the extent to which organizational data are consistent with organizational goals (Izhar et al., 2013).

\section{Model for the Organizational Goals}

Model is simplified to represent the scientific method of a conceptual idea which expected to understand. Model can be a concept, theory or data model and proliferate in organization as a mean of representing the process of the organization by information system (Almeida \& Barbosa, 2009). Information has a relevant role to consolidate the creation of model to represent an activity in the organization. The contribution of ontology to represent the information system is to improve the creation of model ultimately takes place through the organizational goals and it works as a type of relationship to represent the dependency relationship of the organizational goals elements and dependency relationship of organizational data that relate to the organizational goals. As a respond to this, ontology is proposed as part of the organizational goals model to show dependency relationship between organizational data and organizational goals.

\subsection{Implementation of Ontology}

The development of the ontology for the organizational goals model is comprised of the following stages: i) determining the scope, ii) conceptualization and iii) implementation. The ontology is planned to be built to address the following dependency relationship: to address the dependency relationship of organizational goals elements and to address the dependency relationship of organizational data that relate to the organizational goals. The model adopted for building the organizational goals ontology is based on the work of Rao et al. ( 2012), 


\section{MInstitute Macrothink $^{\text {Int }}$}

Sharma \& Osei-Bryson (2008) and Fox et al. ( 1998).

\subsubsection{Determining the Scope of the Ontology for the Organizational Goals}

In order to determine the scope of the organizational goals, ontology is developed to address the relationship of the organizational goals elements (Izhar et al., 2012; Izhar et al., 2013). The purpose of the ontology is determined as being the definition of the dependency relationship representing the organizational goals process and how the process extracts organizational data from organizational data sets in achieving the organizational goals.

\subsubsection{Conceptualization}

Once the scope is determined, the conceptualization phase is developed as an intellectual activity in the construction of the proposed organizational goals ontology. This is aim to structure the knowledge obtained through the process of collecting organizational data and analysing organizational data as an effort to assist domain experts and entrepreneurs for decision-making in achieving the organizational goals.

\subsubsection{Implementation}

The implementation of the ontology for the achievement of the organizational goals consist the role constrained the interpretation model of the dependency relationship of organizational data that relate to the organizational goals so this organizational data can be considered as relevant organizational data. Despite huge volume of organizational data created, it is difficult to identify relevance of organizational data that relate to the organizational goals (Izhar et al., 2013). Therefore, the implementation of ontology reduced irrelevant organizational data because ontology represents the dependency relationship of organizational data that only relate to the organizational goals.

\subsection{Application of the Ontology}

Despite the various initiatives model for the evaluation of organizational process based on ontology ( Fox et al., 1996; Fox et al., 1998; Mansingh et al., 2009; Rao et al., 2012; Rao et al., 2009; Sharma \& Osei-Bryson, 2008), this paper focus on the ontology to evaluate organizational data that relate to the organizational goals (Izhar et al., 2012; Izhar et al., 2013). This process consists of indentifying whether organizational data is relevant correspond in achieving the organizational goals. This identification focused on domain experts and entrepreneurs who contribute in the decision-making process and responsible to identify to what extend the organizational goals are achieved. The evaluation of ontology shows the dependency relationship of the organizational goals and the dependency relationship of organizational data that relate to the organizational goals.

\section{Organizational Goals Ontology}

In this section, we propose the organizational goals ontology as a model to develop a common understanding of the structure and dependency relationships of the organizational goals. It provides the domain experts and entrepreneurs with knowledge to identify the most relevant organizational data in relation to organizational goals. In order to propose the 
organizational goals ontology, we combined several structures that were proposed in previous models ( Fox et al., 1998; Rao et al., 2012; Sharma \& Osei-Bryson, 2008), adopting these models as a reference during ontology development. However, the scope of our organizational goals ontology does not cover all the organizational processes such as activities, physical resources and performance.

Fox et al. ( 1998) focused on structuring the link between organizational structure and behaviour. This is critical for enterprise model development. However, the authors do not emphasise any organizational resources such as data and information because they focus on the roles and activities within the organization. Meanwhile, Sharma \& Osei-Bryson (2008) developed a framework for an organizational ontology in an effort to increase an understanding of the business. However, in this study, the authors do not specifically identify the relationship between organizational resources, such as data, and the organizational goals. In this model, the authors adapted the work of Fox et al. (1998), where the authors discussed the physical resources and role of the organizational model. Recently, Rao et al. (2012) developed an organizational ontology in order to build a knowledge map within the organization. The structure includes the flow of knowledge within the organization in the context of knowledge sharing and knowledge storage. In this model, the authors discussed the organizational resources, as in Sharma \& Osei-Bryson (2008). Another aspect that is similar to Sharma \& Osei-Bryson's work is that both models include business processes. However, Rao et al. (2012) discussed business processes from the organizational goal point of view and Sharma \& Osei-Bryson (2008) discussed business processes from the organizational activity point of view. Most previous studies focused on organizational structure and performance. To our knowledge, very few studies have been conducted on the development of the organizational goals ontology in an effort to evaluate the relationship between organizational data and organizational goals.

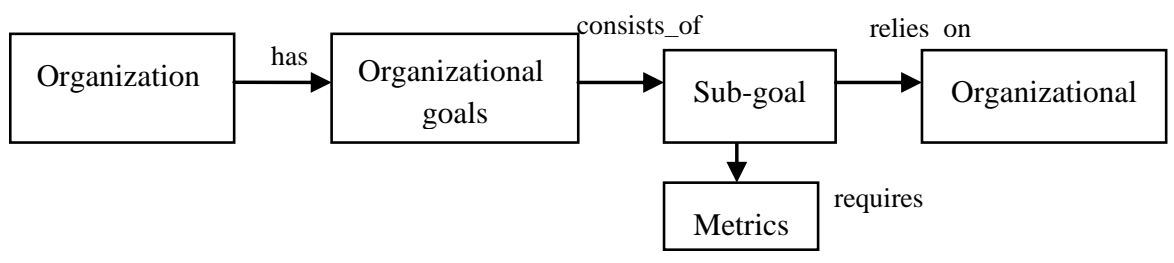

Figure 2. Organizational goals ontology

Based on the above discussion, we proposed the organizational goals ontology as shown in Figure 2, as each organization has many organizational goals and organizational goals consists of sub-goals. These are the organization goal elements which rely on organizational resource which is data. Compare to Sharma \& Osei-Bryson (2008), we focus on the use of organizational data instead of knowledge, information or tools. This is because organizational data is a major resource in every organization and it is important to evaluate the relevance of this data in terms of achieving the organizational goals. We also suggest organizational data is important as information and knowledge to assist the decision-making process. 
In any organization, it is extremely important for the manager to have access to the most relevant data in relation to the organizational goals. Simsek et al. (2009) point out that sharing important data and information can provide the required knowledge to assist successful decision-making. It is crucial for organizations to create and generate new data and evaluate it to enhance decision-making. Different ways of generating new ideas, information and knowledge will help in terms of decision-making and will enable teams within the organization to use the most relevant data to successfully achieve the organizational goals. Data is presented in many forms such as documents and statistics. These data are the most important resources in relation to the organizational goals. In this paper, we define this data as organizational data and refer to this term in most sections of this paper. This is different to several other studies which either did not include metrics at all (Fox et al., 1998; Sharma \& Osei-Bryson, 2008) or only used the metrics to measure the knowledge within the organization (Rao et al., 2012).

\subsection{Organizational Goals Terminology}

In this subsection, we introduce the terminology used in the organizational goals ontology. The terminology defines the organizational goal elements. As shown in Figure 1, every organization has organizational goals that specify the target that the organization aims to achieve. These organizational goals consist of a single sub-goal or several sub-goals. These sub-goals rely on organizational resources which is organizational data. In the rest of this section, we denote an organizational goal as $\mathrm{Org}_{\text {goal }}$ and a sub-goal as $\mathrm{Sub}_{\text {goal }}$.

Note in Figure 2, each arrow " $\rightarrow$ " is defined as an operator function of the organizational goal elements within the organization. The following operators are used:

- has: Organization has Org goal $_{\text {. }}$

- consist_of: Org goal consist_of Sub goal in relation to the $\mathrm{Org}_{\text {goal }}$.

- requires: Sub goal relies_on organizational data.

In Figure 2, an organization is defined as a group of people working on one scope of activity to achieve the organizational goals. An organization involves several elements which make up the organizational goals. We denote organization as

$$
\text { has }(\text { Org, Org goal })
$$

signifying that an organization has organizational goals. In this paper, organizational goals are defined as the most important targets in every organization and involve the process of identifying the aim of the organization. In order to achieve the organizational goals, organizations develop sub-goals. Taking an assumption of a university library as an example, if the main objective or goal is to 'transform student lives through learning', then the sub-goal is to 'create pathways for underrepresented students' and 'substantially increase student enrolments'. We denote organizational goals as

$$
\text { consist_of }\left(\operatorname{Org}_{\text {goal }}, \text { Sub } b_{\text {goal }}\right)
$$

signifying that the organizational goals consists of sub-goals. A sub-goal is defined as an outcome to achieve the organizational goals. It is very important for organizations to identify 
the sub-goals which are necessary to meet the organizational goals. A sub-goal is used as a platform from which to examine the organization's progress toward achieving its main goal. However, as shown in Figure 2, sub-goal relies on resources, which is, organizational data. Organizational data is the most important asset of the organization to enable it to perform its daily activities. For example, if a sub-goal is to 'identify the student background in order to identify the most suitable program' then the possible data is 'data on student background' and 'data on student academic background'. We denote sub-goals as

$$
\text { relies_on }\left(S u b_{\text {goal }}, \operatorname{Org} D_{\text {ata }}\right)
$$

signifying that sub-goals relies on organizational data. In order to improve the understanding of the organizational goals ontology, assuming the process of the organizational goals involves two sub-goals but in real case organization might have more than two sub-goals as shown in Figure 2. In this figure, it is important to identify the value of organizational data that match to the different sub-goals so this organizational data can be considered relevant to the organizational goals. Therefore, metrics approach is important for this measurement analysis so the organizational data can be analysed based on the requirement of domain experts and entrepreneurs to assist their decision-making process.

\subsection{Identify the Organizational Goals}

The term organizational goal is broad and may lead to a misunderstanding of the scope of organizational goals defined in this paper. In the organizational goals ontology, the term organizational goals can be defined differently to advance the understanding on how to merge the decision making scope into the organizational goals scope. Therefore, it is important to carefully define the scope of the organizational goals.

The first step during the implementation process is to identify the main goal and the possible sub-goals that relate to the main goal. In this paper, organizational goals can be defined in many ways. For example, goals might be defined in relation to different requirements, such as what sub-goals relate to the goals? What is the weight of these sub-goals that relate to the goals? And if we examine each sub-goal, can it be considered as a goal itself, as in the example discussed in the case study. This section aims to give a brief idea on how the goal can be defined based on different situations.

For example,

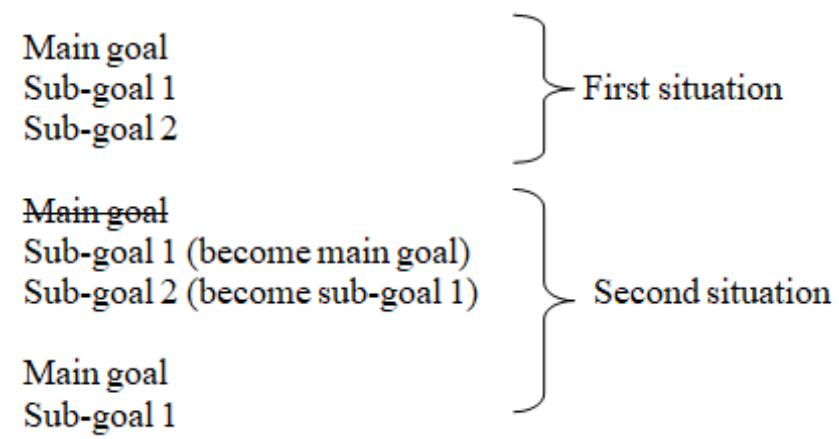




\section{Macrothink Institute ${ }^{\text {TM }}$}

The example shows how the goals could be defined. The example only gives general idea of this concept. The first situation show if the main goal has two sub-goals and this goal can be defined in other way as shown in second situation. The process is further discussed in the next section to show how main goal could be defined based on the dependency relationship of the organizational goals.

\subsection{Identify the Sub-Goals and Variables that Relate to the Organizational Goals}

The second step is to identify the sub-goals and variables that relate to the organizational goals. This step identifies the dependency relationship between sub-goals, variables and organizational goals. It includes on how sub-goals and variables are defined and how the process of evaluating organizational data depend on this dependency relationship.

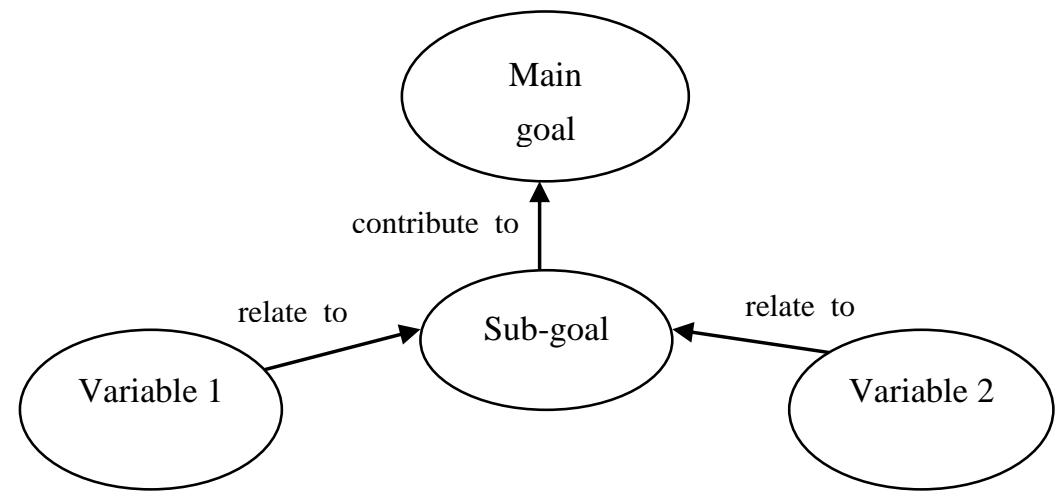

Figure 3. Example of the dependency relationship of sub-goals, variables and organizational goals based on ontology

In order to define the goal, the same process is applied between the sub-goals, variables and organizational goals. In this example, we show three different situations between main goal, sub-goals and variables. These situations represent different ways to identify the main goal based on future domain experts and entrepreneurs on how he/she want to define the main goals.

For example, if he/she wants to focus on sub-goal 1 from situation 1 then this sub-goal 1 become the main goal as shown in situation 2. The same process applied to variable 1 and variable 2. This example is tested in the case study to show how the proposed definition of the organizational goals is defined.

For example, 


\section{Ml Macrothink Institute}

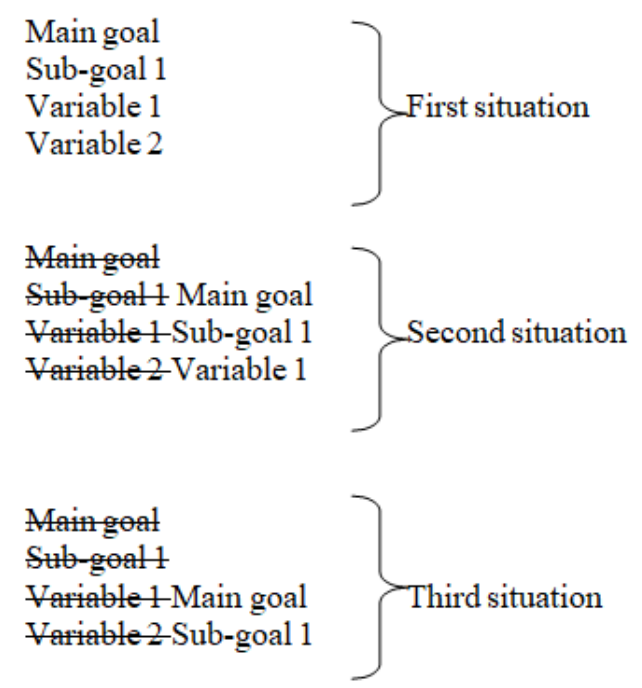

Figure 3 illustrates an example on how the possible sub-goals and variables relate to the organizational goals. However, the example only shows two variables but in real practical case there might be more than two variables or maybe there could only have one variable.

\section{Case study}

In this section, a case study is presented to explain in detail how the proposed organizational goals ontology is implemented and applied in the real world situation. At the same time, this case study aims to explore the real potential of the proposed model so it can be confirmed that this model can be applied in any other cases. The purpose of this case study is to validate the flexibility and reliability of the proposed model to assist domain experts and entrepreneurs in decision-making process in relation to the organization goals. Meanwhile, case study presented in this section is applied to discover any issues or gaps which may be presented during the implementation and how these gaps can be improved. This flexibility also helps to confirm the validity of the organizational goals ontology. The case study consists of several steps to test all aspects of the organizational goals ontology. The steps are used to;

- define the organizational goals,

- identify existing sub-goals and variables that relate to the organizational goals,

- define the relationship of sub-goals and variables to the organizational goals,

- to define metrics as a measurement approach to evaluate organizational data to be considered relevant to the organizational goals.

\subsection{Overview}

Case study is applied based on La Trobe University to evaluate organizational data in relation to the organizational goals. The implementation of case study attempts to identify the level of student satisfaction of La Trobe Student Support Services. To achieve this aim, presented data is examined based on La Trobe University Student Support Services Experiment Report in 2011 (http://www.latrobe.edu.au/student-services/student\%20survey/index.html). The aim of 


\section{Macrothink

La Trobe University Support Services is to improve the university experience by providing services that encourage students to socialize and become involved in things other than books.

The case study of this paper aims to identify the level of student satisfaction of the La Trobe Student Support Services. In order to achieve this aim, data published in the La Trobe University Student Support Services Experiment Report in 2011 (http://www.latrobe.edu.au/student-services/student\%20survey/index.html) is examined. The aim of the La Trobe University Support Services is to improve the students' university experience by providing services that encourage students to socialize and become involved in things other than books. The process of the case study is shown in Figure 4.

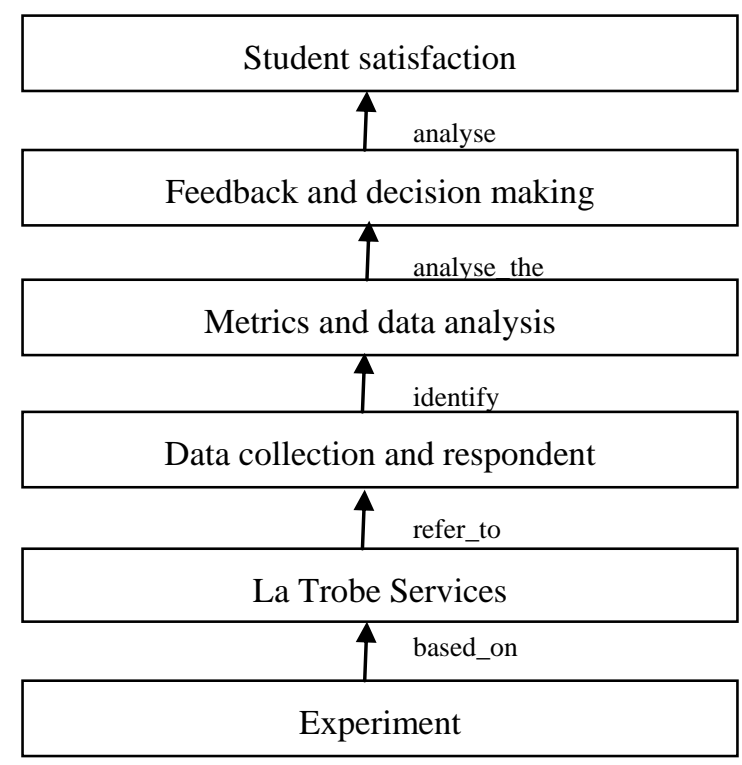

Figure 4. Experiment approach toward student satisfaction

Based on the La Trobe Student Support Services report, the primary objective of the experiment is to provide La Trobe University with a means to identify key student concerns. More specifically, the objectives of the experiment are:

- to identify, prioritise and manage the key issues affecting students,

- to measure the usage of student services offered,

- to provide students with the opportunity to communicate openly and honestly with the management team of the La Trobe Student Services.

The experiment was conducted online which students were invited to participate in the survey by completing the anonymous questionnaire. This confidentiality helps ensure that the true concerns of the students are identified. This survey measuring student satisfaction with the services undertaken by La Trobe University then displayed the total variables of services considered critical to the success of the services. Students were asked to indicate whether they had;

- not used the services but were aware of them,

- have used the services but believe services can potentially improve. 


\section{Macrothink}

\subsubsection{Experimental of the Organizational Goals Ontology}

The development of the organizational goals ontology in this section determined the scope of the case study, which contrasts to the objective of La Trobe Student Support Services. The experiment on the organizational goals ontology addressed the relationship of two different variables evaluated to identify student satisfaction to the La Trobe Student Support Services. Therefore, the scope of goal definition for the case study presented as:

- Goal: Student satisfaction.

- The relationship of the goal is identified based on student satisfaction if they have not used the services and if they have used the services believe services can potentially improve.

In order to evaluate the level of the student satisfaction, data from the case study is measured based on student background. In this case study, two categories of student background is selected from La Trobe University Student Support Services Experiment Report to test the proposed model.

- Faculty consists of Health Science, Law and Management, Science, Technology and Engineering, Humanities and Social Science, and Education.

- Campus consists of Bundoora, Bendigo, Mildura, Shepparton, Albury Wodonga and City.

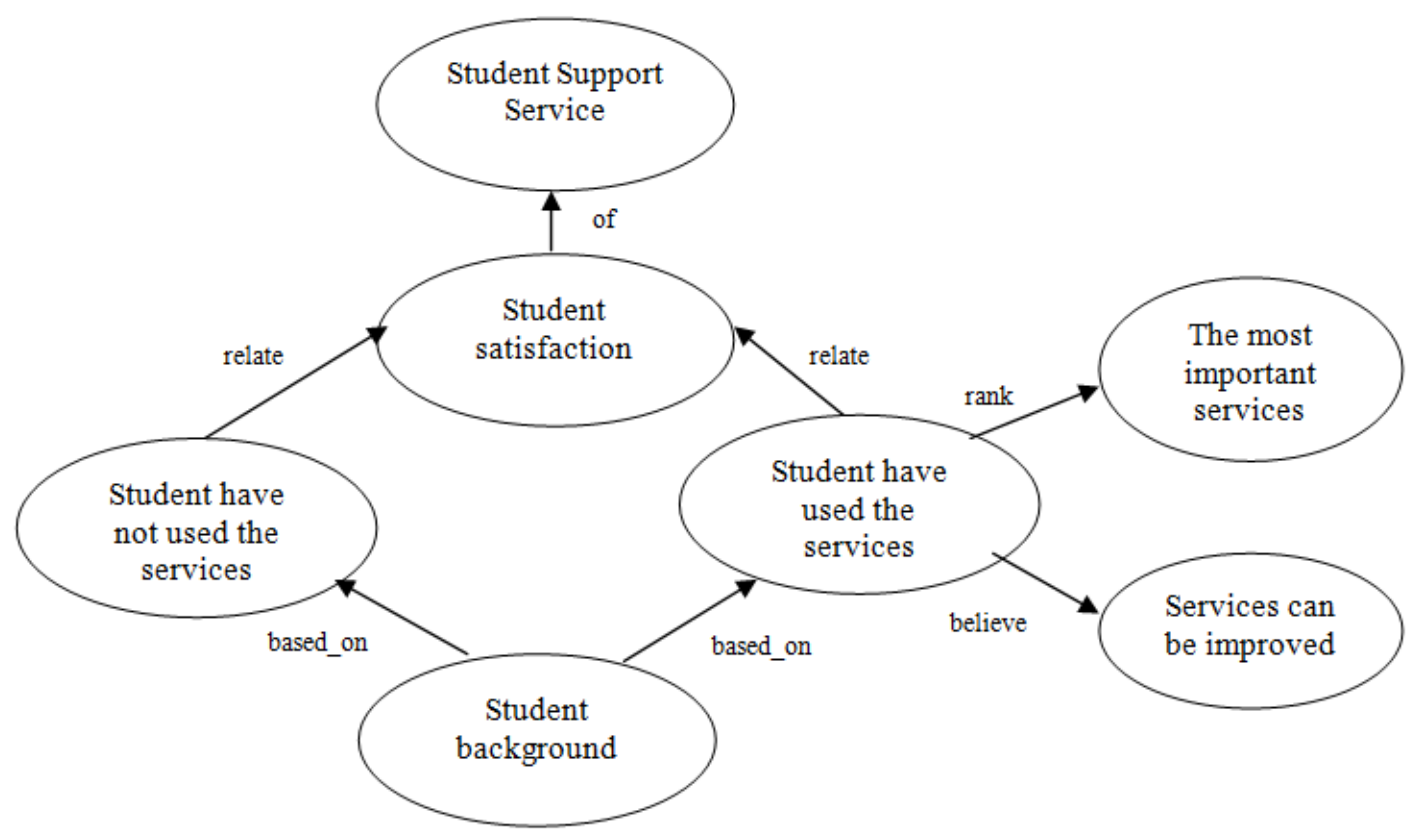

Figure 5. Dependency relationship of student satisfaction in relation to La Trobe University Student Support Services based on organizational goals ontology

Figure 5 structures the knowledge obtained through the process of assigning weights to the dependencies to measure the degree of student satisfaction in the La Trobe Student Support 
Services, based on their background and whether they had used the service or not.

\subsubsection{Evaluation of Experiment Data}

This sub-section identified the number of student satisfaction of La Trobe Student Support Services. Therefore, the processed only include the evaluation the number of student that have used the services. The evaluation indicates the number of student based on student background. Even though the evaluation in this case study only evaluates the number of student that have used the services, it does not mean that the value of student that have not used the services are not important. With respect to the presented data from the La Trobe University Student Support Services Experiment Report, the evaluation in this case study only evaluate the number of student that have used the services to test the flexibility of the proposed model to assist decision making process in relation to the student satisfaction. At this stage of our research, we considered data from student that have used the services are enough test the proposed model.

\subsection{Metrics Definition}

The evaluation of the data is measured from a total number of students that respond to the experiment considered critical to the success of the services provided by La Trobe University. In this evaluation, we selected 11 different services with respect to the La Trobe University Student Support Services Experiment Report. The process determines the total number of student that respond to the experiment based on student background.

- Goal: Student satisfaction of La Trobe's Student Support Services.

- Weight: Student who have used the services believe services can potentially improve.

- Student background: Faculty and campus.

In the case study, to evaluate the level of student satisfaction, the number of student that have used the services are evaluated to identify the overall student satisfaction of the La Trobe Student Support Services. Rank is evaluated for each services and the percentage rank is evaluated as the percentage of scores of student who have used the services to identify the level of student satisfaction. In this case study, metrics for this percentage is determined using ranking number. If the services have duplicate number, rank could give these number the same rank but the duplicate number affect the rank of subsequent number. For example, if 24 appears twice in one list and has rank of 4, then 25 would have a rank of 6.

In this case study, the percentage of the overall student satisfaction was calculated based on the following metrics:

$$
\text { Percentage }=\text { student background }\left(\frac{\text { total number }}{\text { total ranks }} \times 100\right)
$$

In this metrics, number of student that responded to the services is rank from the total set of services. For example in Table 1, rank is identified to define the highest number for every service based on student background. Therefore, results show which service is considered important. However, overall satisfaction of student is identified based on the percentage of this rank. In Table 1, from the set of total range of 11 services, each service has different 
number and rank. Overall satisfaction is identified based on student background which is the campus. Therefore, the results show the total percentage of rank of the student satisfaction of the La Trobe University Student Support Services. Take student from Bundoora campus as an example. In this example, we see career event has 441 number of student who have used this service. Since this service rank 3 from the other services, we see the number for this rank is [441(3)] as the first part of the equation. This process continues through to the end of the equation for every service. Therefore, the overall weight of student satisfaction from Bundoora campus is shown as:

$$
\text { Percentage }=\left(\frac{4002}{441(3)+464(2), \ldots, 1656(1)} \times 100\right)
$$

\subsection{Evaluation of Data}

In this case study, data is evaluated as an effort to identify the value of overall student satisfaction of La Trobe University Student Support Services as shown in Table 1 and Table 2. In order to identify student satisfaction of the La Trobe Student Support Services, the evaluation analysed the total number of student that have used the services and total number of rank to identify the overall student satisfaction based on student background.

Table 1 summarized overall student satisfaction of the La Trobe University Student Support Services based on campus. The table show number of student that have used the services and believe services can potentially improve. These services are ranked but this rank has not been sort from the smallest rank to highest rank. In this table, the results show the overall satisfaction of student from Bundoora campus is $32 \%$. This means student who have used the services considered the services are important than $32 \%$ of other student from other campuses. In the mean time, student from Bendigo campus has $33 \%$ of overall satisfaction from other campuses. The results show that the faculty office has the highest number and ranked 1 for both student from Bundoora and Bendigo campus. The lowest number and rank last is childcare. Student from Albury Wodongo campus has the overall percentage of $30 \%$ which mean student believe the services are considered important than $30 \%$ of other campuses with the faculty office also ranked first and discrimination and harassment support service is ranked last.

On the other hand, the results show the overall satisfaction of student from Mildura campus is $34 \%$ in which the faculty office is ranked first. The results in this category show an interesting number of rank. The results show that clubs, collectives and societies, and disability support service have equal rank which is 8 with the number of 3 . The lowest services also have equal rank which is 10 . Interesting results also discovered among student from Shepparton campus. Overall satisfaction of student from Shepparton campus is $37 \%$. For example, English support service and clubs, collectives and societies is ranked 6 and the lowest rank is 9 for chaplaincy and religious services, childcare, and discrimination and harassment support services in which student have never used these services. Finally, overall satisfaction of student from City campus is $41 \%$ with the faculty office is ranked first and the lowest rank is childcare. 


\section{Macrothink}

International Journal of Human Resource Studies

ISSN 2162-3058

2020, Vol. 10, No. 4

Table 1. Percentage rank of student satisfaction based on campus.

\begin{tabular}{|c|c|c|c|c|c|c|c|c|c|c|c|c|}
\hline & & & & & Albury & & & & & & & \\
\hline Services/ Campuses & Bundoora & Rank & Bendigo & Rank & Wodonga & Rank & Mildura & Rank & Shepparton & Rank & City & Rank \\
\hline Career events & 441 & 3 & 138 & 4 & 46 & 2 & 9 & 5 & 9 & 5 & 4 & 2 \\
\hline Career information and resources & 464 & 2 & 189 & 2 & 36 & 5 & 20 & 2 & 16 & 2 & 2 & 5 \\
\hline Career planning and advice & 315 & 5 & 91 & 6 & 18 & 6 & 12 & 3 & 12 & 3 & 3 & 3 \\
\hline Chaplaincy and religious services & 139 & 8 & 34 & 8 & 9 & 7 & 2 & 10 & 0 & 9 & 1 & 8 \\
\hline Childcare & 32 & 11 & 7 & 11 & 8 & 8 & 4 & 7 & 0 & 9 & 0 & 11 \\
\hline Clubs, collectives \& societies & 366 & 4 & 167 & 3 & 37 & 4 & 3 & 8 & 4 & 6 & 2 & 5 \\
\hline Counselling & 296 & 6 & 120 & 5 & 43 & 3 & 11 & 4 & 11 & 4 & 2 & 5 \\
\hline Disability support & 91 & 9 & 37 & 7 & 7 & 9 & 3 & 8 & 3 & 8 & 1 & 8 \\
\hline \multicolumn{13}{|l|}{ Discrimination and harassment } \\
\hline support services & 33 & 10 & 11 & 10 & 1 & 11 & 2 & 10 & 0 & 9 & 1 & 8 \\
\hline English language support & 169 & 7 & 25 & 9 & 6 & 10 & 5 & 6 & 4 & 6 & 3 & 3 \\
\hline Faculty office & 1656 & 1 & 517 & 1 & 93 & 1 & 54 & 1 & 41 & 1 & 24 & 1 \\
\hline \multicolumn{13}{|l|}{ TOTAL NUMBER/TOTAL } \\
\hline RANK & 4002 & 12512 & 1336 & 4037 & 304 & 1011 & 125 & 365 & 100 & 270 & 43 & 104 \\
\hline Student satisfaction (\%) & $32 \%$ & & $33 \%$ & & $30 \%$ & & $34 \%$ & & $37 \%$ & & $41 \%$ & \\
\hline
\end{tabular}

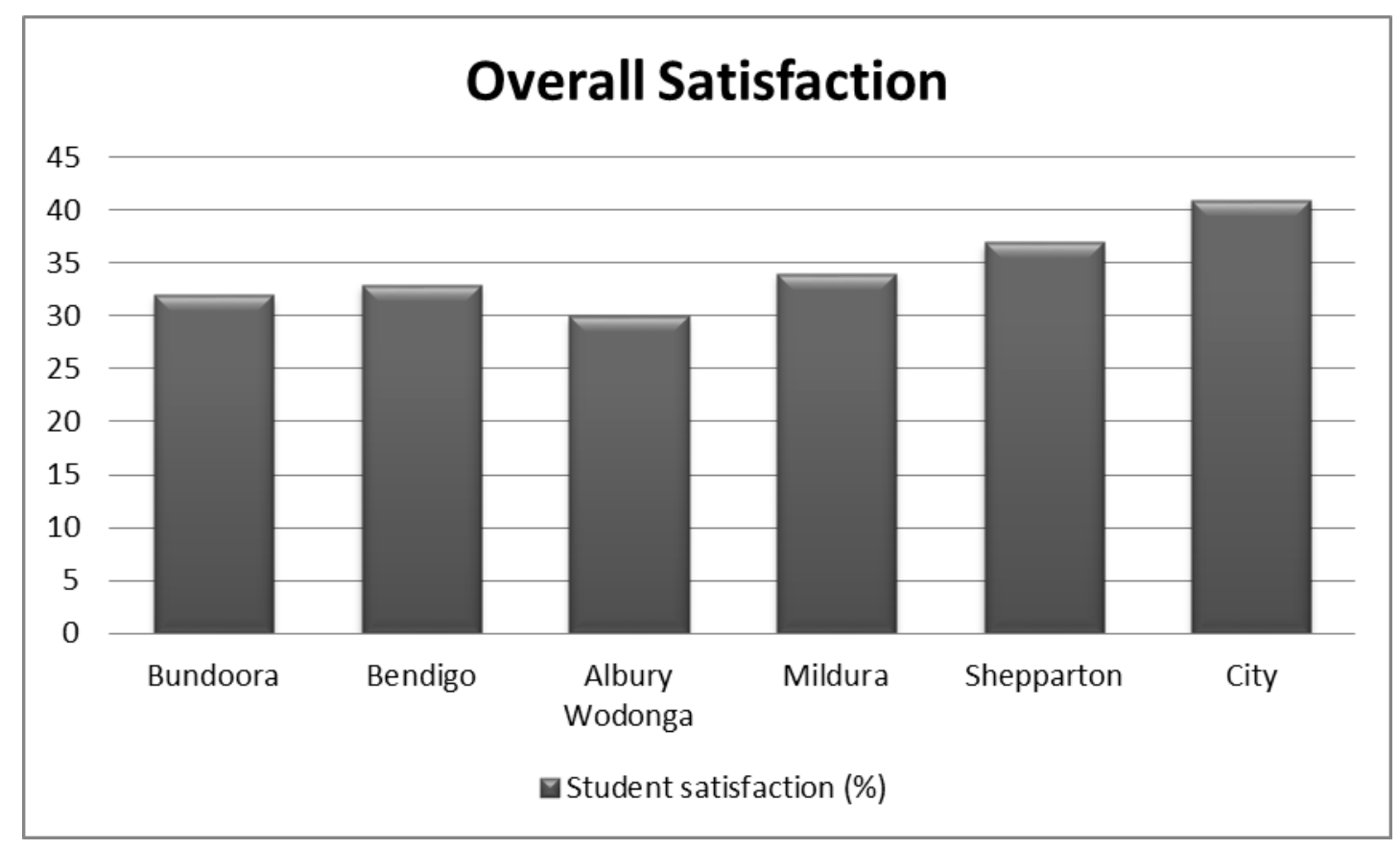

Figure 6. Overall student satisfaction of La Trobe Student Support Services based on campus 


\section{Macrothink}

International Journal of Human Resource Studies

ISSN 2162-3058

2020, Vol. 10, No. 4

Table 2. Percentage rank of student satisfaction based on faculty

\begin{tabular}{|c|c|c|c|c|c|c|c|c|c|c|}
\hline & & & & & Science, & & & & & \\
\hline & Health & & Law and & & Technology \& & & Humanities and & & & \\
\hline Services/ Faculties & Science & Rank & Management & Rank & Engineering & Rank & Social Science & Rank & Education & Rank \\
\hline Career events & 169 & 3 & 191 & 2 & 159 & 2 & 87 & 4 & 39 & 5 \\
\hline Career information and resources & 233 & 2 & 165 & 3 & 159 & 2 & 77 & 6 & 90 & 2 \\
\hline Career planning and advice & 98 & 6 & 149 & 4 & 91 & 6 & 79 & 5 & 32 & 6 \\
\hline Chaplaincy and religious services & 50 & 8 & 33 & 8 & 49 & 7 & 33 & 8 & 20 & 7 \\
\hline Childcare & 10 & 11 & 13 & 11 & 13 & 10 & 11 & 10 & 4 & 11 \\
\hline Clubs, collectives \& societies & 133 & 4 & 112 & 5 & 129 & 4 & 148 & 2 & 56 & 3 \\
\hline Counselling & 122 & 5 & 93 & 6 & 100 & 5 & 113 & 3 & 54 & 4 \\
\hline Disability support & 32 & 9 & 22 & 9 & 40 & 8 & 36 & 7 & 12 & 9 \\
\hline \multicolumn{11}{|l|}{ Discrimination and harassment } \\
\hline support services & 11 & 10 & 14 & 10 & 11 & 11 & 7 & 11 & 11 & 10 \\
\hline English language support & 51 & 7 & 83 & 7 & 37 & 9 & 24 & 9 & 17 & 8 \\
\hline Faculty office & 733 & 1 & 451 & 1 & 471 & 1 & 475 & 1 & 250 & 1 \\
\hline \multicolumn{11}{|l|}{ TOTAL NUMBER/ TOTAL } \\
\hline RANK & 1642 & 4701 & 1326 & 4368 & 1259 & 3916 & 1090 & 3234 & 585 & 1739 \\
\hline Student satisfaction (\%) & $35 \%$ & & $30 \%$ & & $32 \%$ & & $34 \%$ & & $34 \%$ & \\
\hline
\end{tabular}

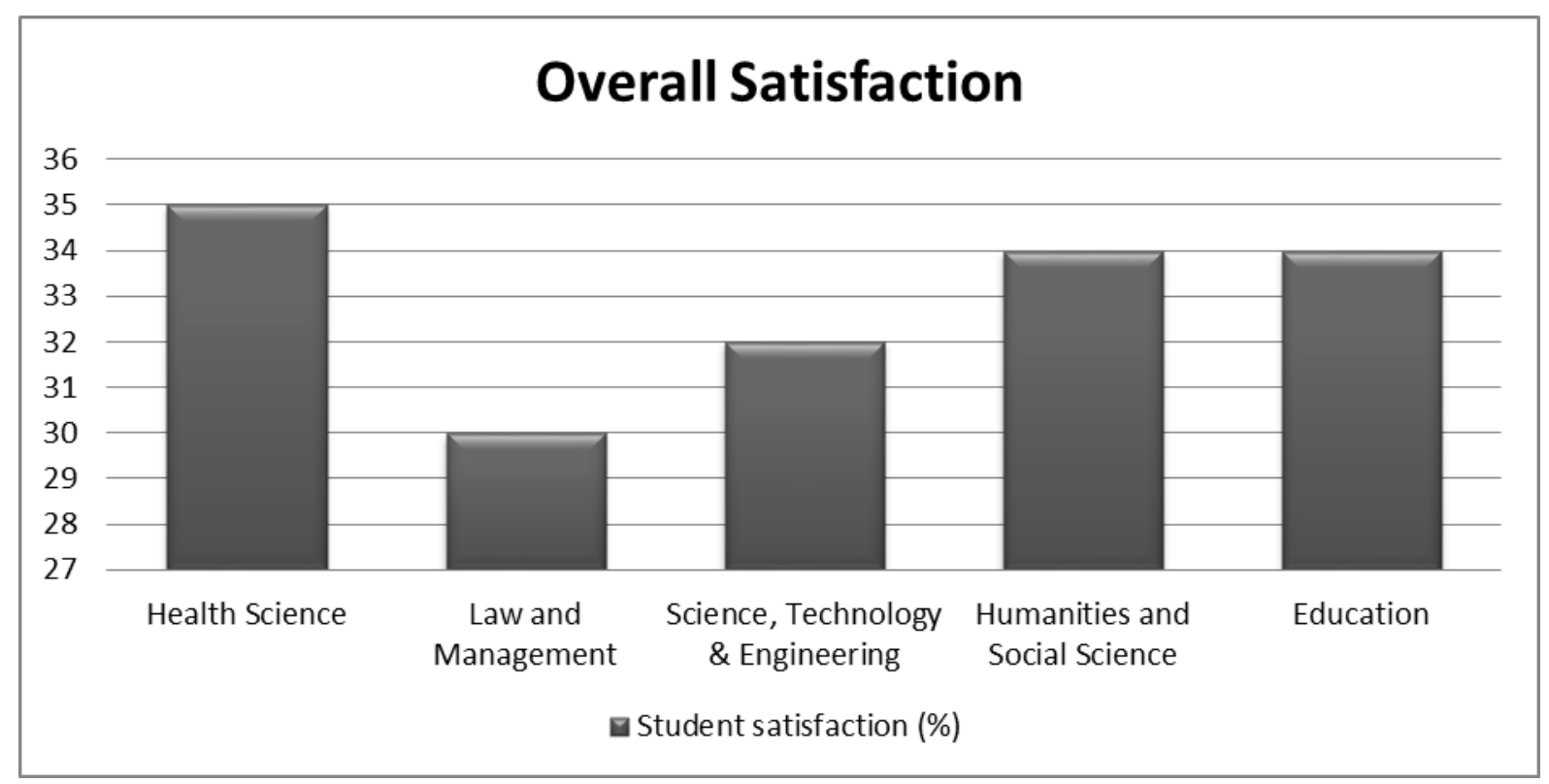

Figure 7. Overall student satisfaction of La Trobe Student Support Services based on faculty

Meanwhile, the results in Table 2 summarize overall student satisfaction of La Trobe University Student Support Services based on faculty. The results show student from which faculty have the highest overall satisfaction of La Trobe University Student Support Services. In this table, the results show the overall satisfaction of student from Faculty of Health Science is 35\%, Law and Management is 30\%, Science, Technology and Engineering is 32\%, Humanities and Social Science is $34 \%$ and Education is 34\%. The results in Table 2 also 
show the number for every service that has been considered important by the student. For example, student from Faculty of Health Science considered the services are important than $35 \%$ of the other faculties with faculty office has been used the most and ranked first. Childcare is ranked last with only 10 number of student have been used this service. At the same time, the results in Table 2 also show that some of these services have equal rank. For example, career events and career information and resources are ranked second from student of the Faculty of Science, Technology and Engineering.

In the nutshell, the results show the overall student satisfaction of the La Trobe University Student Support Services. The results discussed on how the overall satisfaction is evaluated and how the services are consider important to student. Even though the number of services is evaluated and ranked, the evaluation in this case study identified the percentage for services for different student background to identify the level of student satisfaction. Therefore, decision making can be made to identify the overall level of student satisfaction based on different student background.

\section{Discussion}

Organizations accumulate vast amounts of data due to the implementation of information systems which make it easy to collect and store organizational data. Entrepreneurs require organizational data to assist them in decision-making and they need to identify the most relevant data from the vast amounts of available data to support their decision-making. The discussion in this paper is justified based on two main processes, the organizational goals ontology and the metrics as a measurement tool to evaluate organizational data in relation to the organizational goals.

\subsection{Solution from the Organizational Goals Ontology}

There are steps considered in proposing the organizational goals ontology in the case study. Firstly, ontology improved understanding of the goal that defined relationship of student satisfaction based on student have not used the services and student have used the services but believe services can potentially improve. Secondly, ontology integrated the dependency relationship of variables in the case study. Ontology represented the case study structure provided the means to understand the relationship involved in case study.

This ontology developed common understanding of the dependency relationship in the case study. The proposed organizational goals ontology improved the understanding of this dependency relationship that created knowledge for domain experts and entrepreneurs to identify data from 11 types of services that identified the level of student satisfaction. In contrast to the previous studies (Fox et al., 1998; Rao et al., 2012; Sharma \& Osei-Bryson, 2008), proposed organizational goals ontology in this case study cater the relationship of the data and how this data is evaluated and presented as relevant data in decision-making process. Knowledge create in the case study examined the relationship of the La Trobe Student Support Services experiment to the scope, implementation and evaluation of the proposed organizational goals ontology. The outcome of the organizational goals ontology encouraged the development of the organization structure that involved the elements of the organizational 
goals.

In Fox et al. (1998), the authors focused in structuring the relationship between the organization structure and behaviour. This is critical for the enterprise model development. However, the proposed ontology in this paper emphasised organizational data as relevant organizational data. Meanwhile, Sharma \& Osei-Bryson ( 2008) developed a framework of the organizational ontology as an effort to implement the business understanding but the model did not specifically show the relationship of the organizational resource such as organizational data in relation to the organizational goals. The solution based on the organizational goals ontology developed the relationship between the goals in the case study.

\subsection{Solution From the Metrics}

In this case study, metrics are defined to evaluate the percentage of student satisfaction of the La Trobe services. Metrics define the data from the case study in relation to the case study goal. Metrics clarified the case study requirement and analysis. The requirement is designed to accomplish case study scope that flexible with the presented data in the case study. Analysis analysed the requirement of domain experts and entrepreneurs for decision making process. The proposed solution based on metrics concluded three fundamental needs; control, communication and improvement. Control is the ability of the metrics to evaluate and control the source the metrics are measuring. Communication is the ability of the metrics to communicate externally and internally for the purpose of control. Improvement is the ability to identify the gaps for the improvement.

In this paper, determining the impact of data and information is crucial for better decision-making. In the case study, metrics evaluate the data based on case study goal. Metrics is frequently used to evaluate data as in the case study, the evaluation proposed the percentage of student satisfaction which is important for the La Trobe Student Support Services to measure student satisfaction of these services. In contrast to previous approaches on metrics (Alkhattabi et al., 2011; Goel \& Chengalur-Smith, 2010; Rao et al., 2012; Schalken \& Vliet, 2008), metrics proposed for the solution in this paper applied the measurement of organizational data in relation to the organizational goals. Data is evaluated and assisted decision-making process in relation to achieve the organizational goals.

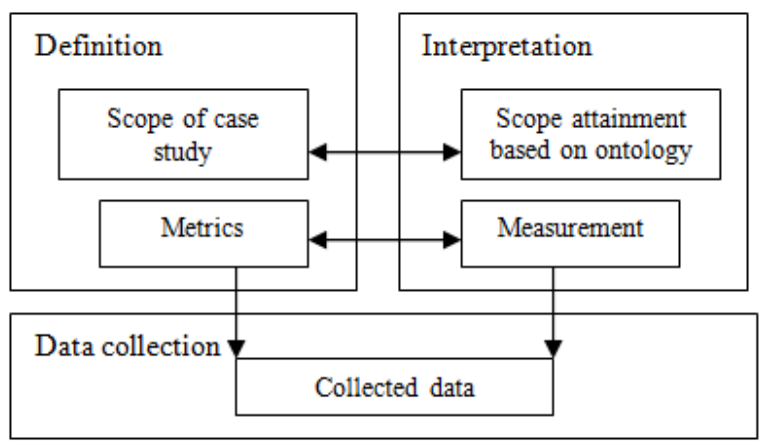

Figure 8. Metrics scope based on the case study

\subsection{Evaluation Outcome From the Case Study and Future Work}


The outcome of the case study concludes that the proposed model is tested to evaluate organizational data that relate to the organizational goals. This is based on several steps for domain experts and entrepreneurs to follow for the future implementation.

Case study is emphasised to evaluate the organizational data that relate to the organizational goals. Assuming that data is collected and goals are defined, domain experts and entrepreneurs define a metrics as a measurement tool to analyse this data in relation to the organizational goals. When analysed data is presented, the value of analysed is changing and this value can be defined in many ways based on how domain experts and entrepreneurs define the main goals. Meanwhile, assuming this value is analysed and presented as a graphical presentation, the comparison of this value is presented to support decision-making process in relation to the organizational goals. Domain experts and entrepreneurs can decide which goals have been achieved more and which goals have been achieved less. The steps are concluded as follows:

- configuring the dependency relationship for the organizational goals,

- generating comparison of the organizational goals,

- evaluate the weight of organizational data that relate to the organizational goals,

- analyse the results,

- decision making process for the achievement of the organizational goals.

The outcome of the case study can be summarized as the methodology show:

- Goal; Identified the goal of case study.

- Data and attribute identification: 11 attributes represent La Trobe Student Support Services provided to the student. These attributes are related to the case study goal.

- Metrics: Weight to evaluate the presented data from the case study to identify the level of student satisfaction of the services provided by La Trobe Student Support Services.

- Data collection: Data in the case study is presented from the experiment conducted by La Trobe Student Support Services.

- Data analysis: The data presented in this case study is evaluated and analysed in relation to the student satisfaction of services.

- Feedback; results is presented and feedback is discussed show the overall student satisfaction of the La Trobe Student Support Services.

The case study is served as approaching steps in understanding the evaluation approach to evaluate organizational data that can assist in the achievement of the organizational goals. As a result, future work can be conducted to extend the organizational goals ontology by expanding the proposed ontology and metrics for future case study. In the meantime, metrics will be extended in measuring future data. For example, we evaluate the percentage of 
student who has used the services. Future work could identify the comparison between student that have used the services and student that have not used the service.

\section{Conclusion}

This paper explained in detail how the methodology is tested and implemented in the real world situation. In Section 1, we discussed the organizational goals concepts. In Section 2, we discussed the existing literature. In Section 3 and Section 4, we developed the organizational goals model based on ontology. In Section 5, we applied the organizational goals ontology to the case study. The case study involves the process on how the goal is identified and how the data presented in the case study is evaluated in relation to the case study goal.

In a nutshell, we suggest the proposed organizational goals ontology is important for domain experts and entrepreneurs to evaluate the relevance of organizational data in relation to achieving the organizational goals. As a result, the organizational goals ontology needs to deal with the inconsistencies, changes and gaps in evaluating the organizational data to the organizational goals. This is because different organizations have different organizational data and organizational goals. The organization can embrace the fact that it is important to have a relevant organizational data to achieve the organizational goals or facing the problem in identifying the relevance of organizational data from the vast amount of it.

\section{References}

Aghdaie, M. H., Zolfani, S. H., \& Zavadskas, E. K. (2014). Synergies of data mining and miltiple attribute decision making. Procedia-Social and Behavioral Sciences, 110(24), 767-776. https://doi.org/10.1016/j.sbspro.2013.12.921

Alkhattabi, M., Neagu, D., \& Cullen, A. (2011). Assessing information quality of e-learning systems: a web mining approach. Computers in Human Behavior, 27(2), 862-873. https://doi.org/10.1016/j.chb.2010.11.011

Almeida, M. B., \& Barbosa, R. R. (2009). Ontologies in knowledge management support: a case study. Journal of the American Society for Information Science and Technology, 60(10), 2032-2047. https://doi.org/10.1002/asi.21120

Azma, F., \& Mostafapour, M. A. (2012). Business intelligence as a key strategy for development organizations. Procedia Technology, 1, 102-106. https://doi.org/10.1016/j.protcy.2012.02.020

Cheng, T., Wang, Y., \& Sun, Y. (2012). Development and application of tender evaluation decision-making and risk early warning system for water projects based on KDD. Advances in Engineering Software, 48, 58-69. https://doi.org/10.1016/j.advengsoft.2012.02.003

Cho, J., Han, S., \& Kim, H. (2006). Meta-ontology for automated information integration of parts libraries. Computer-Aided Design, 38(7), 713-725. https://doi.org/10.1016/j.cad.2006.03.002 


\section{MInstitute Machink $_{\text {Ins }}$}

International Journal of Human Resource Studies ISSN 2162-3058

Christen, P. (2008). Automatic record linkage using seeded neareast neighbour and support vector machine classification. Paper presented at the 14th ACM SIGKDD International Conference on Knowledge Discovery and Data Mining, Las Vegas, Nevada, USA. https://doi.org/10.1145/1401890.1401913

Christen, P. (2012). A survey of indexing techniques for scalable record linkage and deduplication. IEEE Transaction on Knowledge and Data Engineering, 24(9), 1537-1555. https://doi.org/10.1109/TKDE.2011.127

Durham, E., Xue, Y., Kantarcioglu, M., \& Malin, B. (2012). Quantifying the correctness, computational complexity, and security of privacy-preserving string comparators for record linkage. Information Fusion, 13(4), 245-259. https://doi.org/10.1016/j.inffus.2011.04.004

Ferrante, A., \& Boyd, K. (2012). A transparent and transportable methodology for evaluating Data Linkage software. Journal of Biomedical Informatics, 45(1), 165-172. https://doi.org/10.1016/j.jbi.2011.10.006

Fox, M. S., Barbuceanu, M., \& Gruninger, M. (1996). An organisation ontology for enterprise modeling: Preliminary concepts for linking structure and behaviour. Computers in Industry, 29(1-2), 123-134. https://doi.org/10.1016/0166-3615(95)00079-8

Fox, M. S., Barbuceanu, M., Gruninger, M., \& Lin, J. (1998). An organization ontology for enterprise modelling Simulation organizations: Computational models of institutions and groupsAAAI/MIT Press (pp. 131-152).

Goel, S., \& Chengalur-Smith, I. N. (2010). Metrics for characterizing the form of security policies. Journal of Strategies Information Systems, 19(4), 281-295. https://doi.org/10.1016/j.jsis.2010.10.002

Izhar, T. A. T., Torabi, T., Bhatti, I., \& Liu, F. (2012). Analytical dependency between organisational goals and actions: Modelling concept. Paper presented at the International Conference on Innovation and Information Management (ICIIM 2012) Chengdu, China.

Izhar, T. A. T., Torabi, T., Bhatti, M. I., \& Liu, F. (2013). Recent developments in the organization goals conformance using ontology. Expert Systems with Applications, 40(10), 4252-4267. https://doi.org/10.1016/j.eswa.2013.01.025

Lee, Y.-C., Hong, T.-P., \& Wang, T.-C. (2008). Multi-level fuzzy mining with multiple minimum supports. Expert Systems with Applications, 34(1), 459-468. https://doi.org/10.1016/j.eswa.2006.09.011

Lin, C., Lin, C.-M., Li, S.-T., \& Kuo, S.-C. (2008). Intelligent physician segmentation and management based on KDD approach. Expert Systems with Applications, 34(3), 1963-1973. https://doi.org/10.1016/j.eswa.2007.02.038

Mansingh, G., Osei-Bryson, K.-M., \& Reichgelt, H. (2009). Building ontology-based knowledge maps to assist knowledge process outsourcing decisions. Knowledge Management Research and Practice, 7, 37-51. https://doi.org/10.1057/kmrp.2008.37 
Mikroyannidis, A., \& Theodoulidis, B. (2010). Ontology management and evolution for businee intelligence. International Journal of Information Management, 30(6), 559-566. https://doi.org/10.1016/j.ijinfomgt.2009.10.002

Nofal, M. I., \& Yusof, Z. M. (2013). Integration of business intelligence and enterprise resource planning within organizations. Procedia Technology, 11, 658-665. https://doi.org/10.1016/j.protcy.2013.12.242

Omerzel, D. G., \& Antoncic, B. (2008). Critical entrepreneurs knowledge dimensions for the SME performance. Industrial Management and Data System, 8(9), 1182-1199. https://doi.org/10.1108/02635570810914883

Popova, V., \& Sharpanskykh, A. (2011). Formal modelling of organisational goals based on performance indicators. Data \& Knowledge Engineering, 70(4), 335-364. https://doi.org/10.1016/j.datak.2011.01.001

Popovic, A., Hackney, R., Coelho, P. S., \& Jaklic, J. (2012). Towards business intelligence systems success: Effects of maturity and culture on analytical decision making. Decision Support Systems, 54(1), 729-739. https://doi.org/10.1016/j.dss.2012.08.017

Pundt, H., \& Bishr, Y. (2002). Domain ontologies for data sharing-an example from environmental monitoring using field GIS. Computer \& Geosciences, 28(1), 95-102. https://doi.org/10.1016/S0098-3004(01)00018-8

Rao, L., Mansingh, G., \& Osei-Bryson, K.-M. (2012). Building ontology based knowledge maps to assist business process re-engineering. Decision Support Systems, 52(3), 577-589. https://doi.org/10.1016/j.dss.2011.10.014

Rao, L., Reichgelt, H., \& Osei-Bryson, K.-M. (2009). An approach for ontology development and assessment using a quality framework. Knowledge Management Research and Practice, 7(3), 260-276. https://doi.org/10.1057/kmrp.2009.12

Romero, O., \& Abello, A. (2010). A framework for multidimensional design of data warehouses from ontologies. Data \& Knowledge Engineering, 69(11), 1138-1157. https://doi.org/10.1016/j.datak.2010.07.007

Schalenkamp, K., \& Smith, W. L. (2008). Entrepreneurial skills assessment: the perspective of SBDC directors. International Journal of Management and Entreprise Development, 5(1), 18-29. https://doi.org/10.1504/IJMED.2008.015904

Schalken, J., \& Vliet, H. v. (2008). Measuring where it metters: Determining starting points for metrics collection. The Journal of System and Software, 81(5), 603-615. https://doi.org/10.1016/j.jss.2007.07.041

Selma, K., Ilyes, B., Ladjel, B., Eric, S., Stephane, J., \& Michael, B. (2012). Ontology-based structured web data warehouses for sustainable interoperability: requirement modeling, design methodology and tool. Computer in Industry, 63(8), 799-812. https://doi.org/10.1016/j.compind.2012.08.001 
Seng, J.-L., \& Chen, T. C. (2010). An analytic approach to select data mining for business decision. Expert Systems with Applications, 37(12), 8042-8057. https://doi.org/10.1016/j.eswa.2010.05.083

Sharma, S., \& Osei-Bryson, K.-M. (2008). Organization-ontology based framework for implementing the business understanding phase of data mining projects. Paper presented at the International Conference on System Sciences, Hawaii. https://doi.org/10.1109/HICSS.2008.339

Simsek, Z., Lubatkin, M. H., Veiga, J. F., \& Dino, R. N. (2009). The role of an entrepreneurially alert information system in promoting corporate entrepreneurship. Journal of Business Research., 62(8), 810-817. https://doi.org/10.1016/j.jbusres.2008.03.002

Smith, W. L., Schalenkamp, K., \& Eicholz, D. E. (2007). Entrepreneurial skills assessment: an exploratory study. International Journal of Management, 4(2), 179-201. https://doi.org/10.1504/IJMED.2007.011791

Valiente, M.-C., Garcia-Barriocanal, E., \& Sicilia, M.-A. (2012). Applying an ontology approach to IT service management for business-IT integration. Knowledge-Based Systems, 28, 76-87. https://doi.org/10.1016/j.knosys.2011.12.003

Vergidis, K., Turner, C. J., \& Tiwari, A. (2008). Business process perspectives: Theoretical developments vs real world practice. International Journal of Production Economics, 114(1), 91-104. https://doi.org/10.1016/j.ijpe.2007.12.009

Weerdt, J. D., Schupp, A., Vanderloock, A., \& Baesens, B. (2013). Process mining for the multi-faceted analysis of business processes- A case study in a financial services organization. Computers in Industry, 64(1), 57-67. https://doi.org/10.1016/j.compind.2012.09.010

Zandi, F. (2014). A bi-level interactive decision support framework to identify data miningoriented electronic health record architectures. Applied Soft Computing, 18, 136-145. https://doi.org/10.1016/j.asoc.2014.01.001

\section{Copyright Disclaimer}

Copyright for this article is retained by the author(s), with first publication rights granted to the journal.

This is an open-access article distributed under the terms and conditions of the Creative Commons Attribution license (http://creativecommons.org/licenses/by/4.0/). 